fewer than 40 years to make this leap. Developing countries are transitioning even more rapidly. To put it another way, the developed regions first got rich, they then got old. In the developing regions, it is exactly the opposite - with unknown, but likely sobering implications.

The authors also assess countries that are enjoying high rates of longevity, such as Denmark, France and the United States. Comparatively speaking, Canada isn't doing too badly, but can certainly learn from the experiences of these others.

Another section of essays examines the challenges for countries facing rapid population aging in the next 20 to 30 years. Chapters on Africa, China, Latin America offer interesting perspectives.
For example, we learn about the effects of the HIV/AIDS epidemic in Africa and the implications for both grandparents and grandchildren of the "missing generation" of people between the ages of 20 and 40. The chapter on China deals with, among other things, the demographic effect of the low fertility policies of the current government.

The book concludes with an examination of research and program leaders, whose work ranges from biology to the effect of the new longevity on retirement security - an issue of no little importance given the recent economic downturn.

All in all, the aging of populations across the globe should be considered a great leap forward, reflecting a rousing victory over childhood disease and premature mortality. However, not all countries nor all people age equally well. And certainly, the poor grow old less salubriously and happily. This book offers much information and food for thought as we continue along life's journey - both as individuals as well as citizens of our aging planet.

\section{A. Mark Clarfield MD}

Department of Geriatrics, Soroka Hospital

Ben Gurion University of the Negev Beer-Sheva, Israel

Dr. Clarfield is the international affairs editor of the Journal of the American Geriatrics Society.

\title{
Chisholm, WHO and the pursuit of the public's health
}

\author{
Brock Chisholm, the World Health \\ Organization, and the Cold War \\ John Farley \\ UBC Press; 2008. 254 pp $\$ 85.00$
}

$\mathrm{W}$ hether by coincidence or by design, 4 remarkable books that express the ideal of peace through health, the goal of the World Health Organization, were published in 2008, coinciding with WHO's 60th anniversary. And to this Canadian reviewer the fact that all their authors and editors happen to be Canadian is an expression not of chauvinism, but of legitimate pride.

Crimes Against Humanity, by Adam Jones of the University of British Columbia Okanagan; this reviewer's book, Concepts and Practice of Humanitarian Medicine; Peace through Health (page 1234), by Neil Arya and Joanna Santa Barbara of McMaster University; and John Farley's book embody in their own ways what another Canadian, Dr. George Brock Chisholm (1896-1971), envisioned and practised as the first directorgeneral of WHO.

Based on an extensive search through the archives of WHO and related records, Brock Chisholm is an attempt by

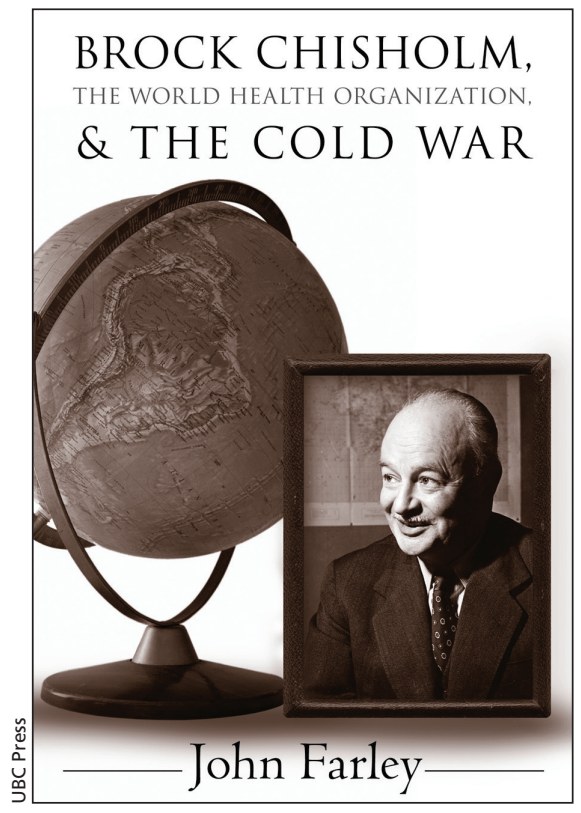

Farley, a Dalhousie University medical historian, to clarify the often entangled relationships between an idealistic leader, a fledgling organization for a new world order and a pitiless Cold War confrontation. Being by design limited in time and scope, the book is an insightful account of that first decade, without pretending to be a biography of Chisholm or the history of WHO. Nonetheless, much transpires on the personality of the leader, the politics of the organization, and the postwar competition of ideologies that soon turned into bitter animosity, considerably detracting from the objectives, performance and efficacy of the organization.

This book will be of interest to medical historians, health planners and social scientists and is a vast depository of documentation for Canadian politologues, students of health policy and international administrators.

The author begins with an account of Chisholm's life, from a young, decorated Ontario soldier to physician, psychiatrist, major-general, deputy minister of health at the federal level, representative to the United Nations and thence to WHO. In light of this exceptional professional climb, one wonders why Farley reports that "Chisholm had been a surprising choice" as the first director-general of WHO when no document or statement alludes to any surprise. Indeed, being initially sent from Health Canada to the UN might seem surprising, but once in the international milieu Chisholm persistently climbed by the votes of his peers, all experts and potential competitors. Norman Howard-Jones, the historian of WHO and no soft-spoken judge, is categorical about this: "He was the natural choice." 
The author's ambiguity also translates in other ways; indeed whether through indecisiveness or concern for impartiality Farley lets some doubts persist that lead to vague interpretations and sometimes give the impres-

sion of a dreamy, impractical man with wooly ideas on Being outside the club was an advantage.

ters in public health, but he knew how to surround himself with the best experts of the time and had confidence in youth. His directors of finance and publications were both aged 38 when appointed, and I recall when he officiated at our medical graduation, his passionate message was: "safeguard your such issues as poverty, family planning, peace, social services and medical coverage. That opponents during the Cold War might have thought this and used it against him may be understandable, but that another Canadian author should even today think that Chisholm was "a bit of a second rater" and that there was "mieux" (his italics) is untenable. ${ }^{1}$ Yes, like most people, Chisholm had his weaknesses and idiosyncrasies and he did not hold a mas- youthful vision and work health into social justice." And as his objective was the public's health rather than traditional public health, his being from outside the club should be seen as an advantage, as indeed it proved to be.

A postscript to the book would also have shown how much his visionary ideas have turned out to be not that illusory after all; to take just 1 example, the relationship between poverty and health, for which he was "crucified" by some at the time.

As an international organization, $\mathrm{WHO}$, even in the earliest years suffered from its members' nationalistic interests and lack of political will, exacerbated by the Cold War. The hot tensions were not particular to Chisholm's period - 4 of his successors faced similar problems — but it was he who first confronted them and, given the maddening complexities, it is to the credit of his capacity for damage control that the ship maintained its course and has safely sailed through its 60th year.

\section{S. William A. Gunn MD \\ Retired surgeon \\ Bogis-Bossey, Switzerland}

\section{REFERENCE}

1. Bliss M. "W.H.O. is Brock Chisholm?" Literary Review of Canada June 2008: 28-9.

\section{Health as a bridge to peace}

\section{Peace through Health: How Health Professionals Can Work for a Less Violent World \\ Neil Arya and Joanna Santa Barbara Kumarian Press; 2008. 341 pp \$39.95}

$\mathrm{P}$ eace through Health is a significant book that expresses and establishes the role of medical practitioners in the promotion of peace through their services in health, what WHO calls health as a bridge to peace.

Far from sounding like an idealistic slogan or impractical wishful thinking, the book's 27 chapters, written by 30 experienced researchers, practitioners or teachers with field exposure to the multifaceted aspects of health, disease and trauma in conflict and war (read peace-lacking) situations, describe the fundamentals of understanding, diagnosing and preventing, as well as possit ble therapies in the promotion of health as a contributor to peace.

We traditionally define and talk about war using the language of politics, a borrowed language in which we are not particularly adept. But what happens when a conflict is seen

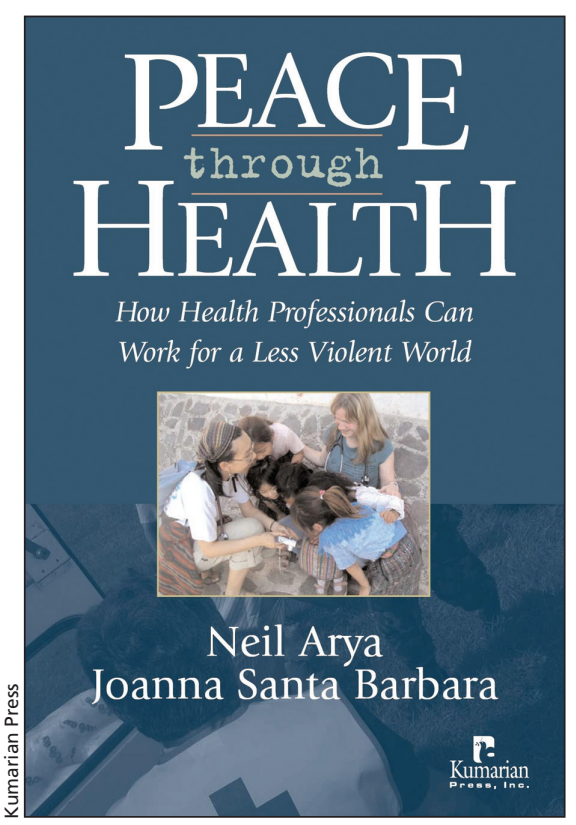

through the doctor's perspective? As distinct from politicians, can health professionals participate in mediation, mitigation and prevention of conflicts, and therefore promote peace? The book's answer is Yes.

As early as 1948 the Constitution of WHO stated that "the health of all peo- ples is fundamental to the attainment of peace and security." And as the authors amply demonstrate, the converse is true: health is strengthened through peace. Indeed the 1986 Ottawa Charter of WHO stresses that the fundamental conditions and resources for health are (in this order) peace, shelter, education, food, income, stable ecosystem, sustainable resources, social justice and equity. To the uninformed these may sound quite far from health or peace, but detailed case records make these assertions convincing and, indeed, invite for action. Readers will be proud that they belong to the profession that is committed to these humanist issues and can do something about them.

\section{S. William A. Gunn MD \\ Retired surgeon \\ Bogis-Bossey, Switzerland}

Dr. Gunn was a lecturer in History of Medicine and Science at the University of British Columbia in Vancouver before joining the World Health Organization. He is the founding president of the International Association for Humanitarian Medicine. 